See discussions, stats, and author profiles for this publication at: https://www.researchgate.net/publication/326785435

\title{
Psychosocial Interventions for Mental Illness among LGBTQIA Youth: A
} PRISMA-Based Systematic Review

Article · August 2018

DOI: 10.1007/540894-018-0090-7

CITATION

1

2 authors:

Emily Van Der Pol-Harney

University of Technology Sydney

1 PUBLICATION 1 CITATION

SEE PROFILE
READS

275

John McAloon

University of Technology Sydney

14 PUBlications 43 CITATIONS

SEE PROFILE

Some of the authors of this publication are also working on these related projects:

Project A Systematic Review and Meta-analysis on the Effectiveness of Parenting Interventions that Include Self-Compassion Promoting Components View project

Project Early Career Grant 2017- Development of a Standardised Model for Experiential Placements View project 


\title{
Psychosocial Interventions for Mental Illness among LGBTQIA Youth: A PRISMA-Based Systematic Review
}

\author{
Emily Van Der Pol-Harney ${ }^{1}$ John McAloon ${ }^{1}$
}

Received: 20 March 2018 / Accepted: 14 July 2018

(c) Springer Nature Switzerland AG 2018

\begin{abstract}
Lesbian, Gay, Bisexual, Transgender, Queer, Intersex and Asexual (LGBTQIA) youth experience a unique range of psychosocial stressors often culminating in poor mental health outcomes. A systematic review of trials that evaluated psychosocial interventions for LGBTQIA youth aged 12-25 was undertaken to evaluate the effect of treatment components and participant-related variables on treatment outcome. The results suggest that creating safe, accepting places, discussion of shared experiences, and using a cognitive behavioural or attachment-based family therapy framework significantly decreased depression, sexual minority stress, anxiety and drug and alcohol use, and enhanced participant approval. LGBTQIA youth had poorer baseline mental health than non-LGBTQIA youth and experienced greater improvements. Further experimental research is needed to define effective treatment components and relevant individual factors to maximise treatment efficacy.
\end{abstract}

Keywords LGBTQIA $\cdot$ LGBT $\cdot$ Youth $\cdot$ Treatment $\cdot$ Minority stress $\cdot$ Mental health $\cdot$ Review

\section{Introduction}

Youth is an emotionally and physically challenging transitional period wherein youth are establishing their identities, forming peer and romantic relationships, and defining their values independent of their caregivers. Understandably, the challenges of youth are associated with increased risk of mental health problems. Suicide is the second leading cause of death in 10-24 year olds, with $8 \%$ of adolescents attempting suicide annually and another $20 \%$ having serious thoughts and intent to (CDCP 2012; Heron 2017). In adolescence, girls are twice as likely to self-harm as boys while completed suicide is sixfold higher in boys than girls (Gandhi et al. 2015; McMahon et al. 2014). The prevalence of anxiety disorders among youth worldwide has been reported to be as high as $28 \%$, depressive disorders as high as $20 \%$, and substance-use disorders in the order of $14 \%$; with $75 \%$ of individuals who experience mental illness within their

John McAloon

John.McAloon@uts.edu.au

Emily Van Der Pol-Harney

Emily.VanDerPol-Harney@alumni.uts.edu.au

1 University of Technology Sydney Psychology Clinic, Level 2, Building 7, 67 Thomas Street, Ultimo, NSW 2007, Australia lifespan developing first experience symptoms before age 25 (Mental Health Foundation 2016). These figures suggest the presence of risk factors unique to this developmental period and the specific challenges encountered in adolescence.

\section{Mental Health of LGBTQIA Adolescents}

Mental health risks are even higher among youth who identify as lesbian, gay, bisexual, transgender, queer, intersex or asexual (LGBTQIA). These terms combine the concepts of sexual orientation (i.e., lesbian, gay, bisexual) and gender identity (i.e., male, female, non-binary). Figures across Western countries indicate that approximately $11 \%$ the population identify as LGBTQIA; yet are disproportionately affected by mental illness, with $28 \%$ of LGBTQIA adolescents reporting suicidal ideation annually, and 15-40\% attempting suicide (Levy et al. 2016; Mosher et al. 2005; Smith et al. 2003). More than a third of transgender youth report clinically significant depressive symptoms, more than half report having thoughts of suicide, and approximately one-third have attempted suicide (Olson et al. 2015). Importantly, in transgender adolescents, self-harm and suicidal behaviors mimic those of the gender that they are transitioning to, such that higher rates of suicide attempts and self-harm behaviors are seen in those transitioning from female-to-male than from male-to-female (Haas et al. 2014; 
Peterson et al. 2017). LGBTQIA youth aged 12-18 are twice as likely as heterosexual age-peers to attempt suicide and have higher levels of depression, substance abuse and eating disorders. In addition, they are more likely to be homeless (likely due to greater instances of parental rejection) and are more often subjected to bullying which can lead to high school absenteeism and drop-out. These youth are at higher risk of sexual, physical and psychological abuse from their caregivers, which partially accounts for the 1.6- to 3.9-fold risk of PTSD (Roberts et al. 2012). Besides elevated PTSD risk, childhood abuse is well documented to have significantly deleterious effects on mental and physical health, and psychiatric treatment seeking (Spataro et al. 2004; Springer et al. 2007). Each of these aversive experiences and challenges introduces significant psychological stress and longterm health risks which may further serve to widen inequalities (Birkett et al. 2009; Connolly et al. 2016; Justice 2016; Lowry et al. 2017; Russell and Joyner 2001).

The mental ill health outcomes disproportionately faced by LGBTQIA youth do not appear to improve in adulthood. LGBTQIA adults are 2-4 times more likely to attempt suicide, and have incidences of depression, anxiety and substance use 1.5-3 times higher than heterosexual adults (ABS 2007; King et al. 2008). Transgender adults are 11 times more likely to attempt suicide than the general population, accounting for $35 \%$ of transgender adults; they are 18 times more likely to have suicidal thoughts, 6 times more likely to self-harm, have a fivefold increased risk of depression, and threefold of anxiety disorders (NLHA 2016). These statistics suggest that LGBTQIA youth experience unique stressors and developmental challenges that increase their risk of mental illness.

Minority stress theory offers an explanation for these unique risk factors. It posits that individuals of minority groups are often subject to prejudice and stigma, resulting in unique stressors with adverse effects on mental and physical health, risk behaviors and quality of life (Meyer 2003). Four major unique stressors are experiences of harassment and abuse; identity development and internalized homophobia; identity disclosure and associated rejection fears; and developing relationships with sexual minority peers (Safren et al. 2001). These four factors may also encompass experiences of violence, bullying, stigmatization, everyday discrimination and micro-aggressions, real or perceived discrimination or rejection from peers or parents, opportunity loss related to employment and education, higher rates of sexual and physical assault, losing friends after coming out, stresses of belonging to a homophobic religious community or family, parents not knowing about, or reacting negatively to their sexuality; and ongoing negative reactions and interactions due to sexual orientation (D'augelli 2002; Hall 2018; Higa et al. 2014; Katz-Wise et al. 2016). Fears of discrimination may delay treatment seeking such that mental health issues are not detected, symptoms escalate and treatments are less likely to be effective (Leonard et al. 2012). Similarly, there is often a 10-year gap between recognizing and disclosing gender incongruence, dysphoria or same-sex attraction associated with fears of threats to one's education or career, or being of higher socioeconomic status, which may be an important within-group risk factor to explore (Olsen et al. 2015; Savin-Williams and Diamond 2000). These factors are associated with compounded chronic strain, increased mental health problems, suicidality and engagement in risky sexual and substance use behaviors, with this pattern stronger for LGBTQIA than heterosexual individuals also experiencing victimization (Bontempo and D'Augelli 2002; Kuyper and Fokkema 2011; Meyer 2003). It has also been found that common adolescent struggles are often amplified for LGBTQIA adolescents in intensity, frequency, salience and meaning (Safren et al. 2001).

Beyond common challenges faced by all LGBTQIA individuals, recent research has identified differences within the LGBT community, which have significant implications for treatment approaches. For example, gay and bisexual men experience higher rates of depression, panic attacks and psychological distress, while lesbian and bisexual women experience higher rates of generalized anxiety disorder than their heterosexual counterparts (Cochran et al. 2003). Within certain populations, young bisexual women are at the highest risk of non-suicidal self-injury and low treatment-seeking compared to heterosexual and lesbian youth, with the latter at the lowest risk (Zaki et al. 2017). Others have found, however, that young lesbians may be at higher risk as parental support isn't as strong a protective factor for mental health as it is for most adolescents (Watson et al. 2016). Interestingly, non-heterosexual daughters tend to receive more parental support and acceptance than non-heterosexual sons due to greater societal tolerance of female sexuality (Kane 2006; Katz-Wise et al. 2016). While rates of mental health are higher within the LGBT community than the general population, LGBT youth are not a homogenous group and thus demonstrate variability in their responses to stressors. All are not at risk of negative health outcomes as a result (SavinWilliams 2001). Thus it is important to identify specific factors that increase risk for poor outcomes as well as protective factors that can be targeted to improve health outcomes.

The aforementioned evidence for minority stress theory suggests that the risk factors associated with mental illness, self-harm and suicide in sexual minority youth are largely socially determined. Parental rejection also has significantly deleterious impacts including predicting depression, suicidality, risky drug use, sexual risk behaviors, we well as interrupting parent-child relationships which has implications for subsequent adult relationship quality (Katz-Wise et al. 2016; Ryan et al. 2009; Yadegarfard et al. 2014). Although many family members are eventually accepting of their children's 
sexuality, many will initially not be, and half of these youth will be verbally abused by parents or siblings (D'Augelli 2003). Unfortunately, not only is parental support a major protective factor against mental ill-health, but LGBTQIA youth may be less likely to receive this support immediately following 'coming out' (Needham and Austin 2010). The importance of parental acceptance points towards the necessitation of psychoeducation for parents on the positive potential of parental support, the negative impacts of parental rejection and disapproval, and also biological and psychosocial factors underlying sexual orientation and gender identity.

Protective factors that can help buffer minority stress include individual coping skills, self-acceptance, selfesteem, and perception of sexuality as a positive and unique trait; and interpersonal factors such as a strong sense of ingroup acceptance and solidarity, involvement in LGBTQIA groups, open discussion about one's identity and struggles, social support and connectedness, school safety, perceived caring from adults, and parental acceptance and support (Bontempo and D'Augelli 2002; Eisenberg and Resnick 2006; Hall 2018; Higa et al. 2014; Meyer 2003; Ryan et al. 2009). Open discussion with social supports likely helps individuals to re-appraise negative experiences, address unhelpful cognitions and enhance resilience (Alessi 2014; Kertzner 2001). As a protective factor in adolescence, family support is crucial. Evidence suggests that while peer social support eventually leads to reduced mental illness, it's magnitude is less than familial support (McConnell et al. 2016; Watson et al. 2016). Furthermore, family support and acceptance has been linked to lower levels of depression, substance abuse, suicidal ideation, and greater self-esteem, physical health and social support within LGBTQIA youth (Katz-Wise et al. 2016). Encouragingly, recent research suggests between 89 and $97 \%$ of youth receive positive parental responses, and that parents generally become more accepting over time (Padilla et al. 2010; Rosario and Schrimshaw 2013). This does however beg the question: if parental acceptance and support is so crucial to the mental health of LGBTQIA youth, why is there still such a high prevalence of mental illness and suicidality in the face of trends towards greater acceptance?

\section{Therapies Targeting the Unique Needs of LGBTQIA Youth}

Therapies adapted to the unique needs of LGBTQIA youth have been developed, both medical and psychological. Medically, transgender adolescents and those in emerging adulthood may seek puberty suppression, hormonal treatment, cosmetic, and gender reassignment surgery. There are few controlled studies in this area, and findings are mixed, with some studies indicating a heightened risk of attempted and completed suicide, mortality, psychiatric illness and medical risks in those seeking identity-affirmative medical therapies, and others reporting improvements in gender dysphoria, body image concerns, behavioral problems, psychological health, quality of life and sexual function (Asscheman et al. 2011; Connolly et al. 2016; De Vries et al. 2014; Dhejne et al. 2011; Murad et al. 2010; Newfield et al. 2006). These mixed findings suggest the need for the development of LGBTQIA-specific psychological therapies to address emotional and social challenges experienced in transition by transgender youth.

A few promising psychological therapies adapted to the needs of LGBTQIA individuals have emerged in recent years. Gay-affirmative psychotherapies aim to promote self-acceptance and to recognize the impact of societal homophobia on self-identity. Pachankis et al. (2015) conducted a randomized control trial (RCT) implementing an LGB-affirmative cognitive behavioral therapy (CBT) called effective skills to empower effective men (ESTEEM) for gay and bisexual men. The intervention focused on reducing unique stressors through addressing maladaptive coping strategies, cognitive restructuring, exposure, mindfulness, emotion regulation skills, motivational enhancement, and building efficacy in coping with sexuality-related rejection and stigma. This therapy led to significant improvements in depressive symptoms, alcohol abuse and sexual compulsivity, and lead to small improvements in minority stress and anxiety symptoms. It is likely that some therapeutic elements from the treatment of adults would generalize effectively to an adolescent population.

Therapeutic elements that LGBTQIA individuals in emerging and later adulthood have found helpful and unhelpful within the therapeutic setting have been identified (Israel et al. 2008). Helpful factors included therapist warmth, confidentiality, knowledge and respect, setting goals and homework, and teaching coping, anger management, and communication skills. Unhelpful factors involved therapist disengagement, judgment, invalidation, and imposition of their own beliefs and views. Overall, the helpful psychological treatments were found to improve mental health, quality of life, relationships, and self-acceptance. While many of these therapeutic factors would generalize to the general population, there seems to be an increased focus on openness and acceptance, perhaps in the context of increased risk of harassment and victimization within this community. While these studies show promise in adapting therapies to the treatment of LGBTQIA youth, the alarming suicide and mental health statistics suggest that there is further work to be done.

\section{The Current Study}

While there is a plethora of evidence that LGBTQIA youth are at higher risk of mental illness and social disparities, there is a lack of research indicating the specific treatment 
adaptations necessary, or what individual factors (e.g. gender identity, age, psychiatric comorbidities, or co-occurring medical interventions) influence treatment outcomes within this population. While medical components of treatment have been found to be helpful in reducing psychological distress in some, there is a need to understand specific psychotherapy components that contribute to better outcomes for transitioning youth not benefiting from medical treatments, or other youth with diverse sexual identities experiencing mental illness. Considering the unique set of risk and protective factors present within this population, it is likely that treatment specifically tailored to the risk factors, needs and presenting concerns of LGBTQIA youth would be more effective than non-tailored treatments. Ideally, available research evidence should be investigated to integrate the existing literature and to provide evidence for effective decision making in treatment within this population. It needs to be established whether certain treatment components consistently show greater efficacy/effectiveness over others, and whether certain individual characteristics lead to varied treatment outcomes.

A systematic review of the literature is proposed to describe current psychological therapies developed for use with adolescents experiencing the unique range of risk factors often associated with identifying as LGBTQIA. The review will search the databases Medline, PsycINFO, Scopus, Web of Science, and Cochrane Central Register of Controlled Trials, using search terms encompassing broad variants on the terms mental health, psychiatric disorders, self-harm and suicide; adolescents; identifying as LGBTQIA; and receiving psychological therapy. Literature from the year 2000 onward will be searched. The review aims to inform the development of more effectively targeted mental health treatments within schools, youth centers, and healthcare settings and to advise health professionals of ways to create more inclusive therapeutic environments. In combination with medical therapies, if certain treatment components are found to be more efficacious than others, these findings could ease the pressures of transitioning. Furthermore, effective treatment may enhance engagement in therapy and contribute to a reduction in dropout rates.

\section{Methods}

\section{Protocol and Registration}

This systematic review was conducted in accordance with PRISMA guidelines, registered under PROSPERO CRD42017052549 (Moher et al. 2009; Shamseer et al. 2015). The review methodology was developed to follow the procedural outlines from the Cochrane Handbook for systematic reviews (Higgins and Green 2011). No ethics approval was required as no direct human data was collected.

\section{Eligibility Criteria (PICOS; Higgins and Green 2011)}

\section{Participants}

Eligible studies were those that included participants aged 12-25 and identifying as LGBTQIA. Ineligible studies were those that included participants who were incarcerated, or had cognitive, autism spectrum or other neurodevelopmental disorders. This age range was selected in order to observe factors influencing the developmental periods of adolescents aged 12-28, and those in emerging adulthood, aged $18-25$; as both of these transitional periods can be considered to involve considerable exploration of identity, relationships, and therefore sexuality and one's place in their social environment.

\section{Interventions}

Eligible studies evaluated psychological treatment programs for mental illness, or school or community-level interventions targeting mental health through other psychosocial factors.

\section{Comparison}

Studies were included with our without control groups. Experimental and quasi-experimental designs were included whether they included a comparison group (i.e., randomized to treatment, control group, waitlist or to treatment as usual) or not (no comparator, trial, pilot etc.).

\section{Outcomes}

Studies were included if they measured psychosocial stressors or psychiatric symptoms with at least one standardized screening interview or questionnaire prior to inclusion in the trial. Studies were also required to apply an intervention and report the impacts on psychosocial outcomes on the basis of assessment with at least one of these measures. For the purposes of this review, a standardized screening interview or questionnaire must have published, peer reviewed psychometric data.

\section{Study Designs}

Studies were included if they were published in a peerreviewed journal from 1st January 2000 until 6th May 2018 The commencement date was chosen because changes to the psychological assessment, diagnosis and treatment of sexual orientation represented in the DSM-IV were largely 
consolidated with the publication of the DSM-IV-TR in 2000 (APA 1994, APA 2000). Study designs included RCTs, prepost open trials and retrospective research designs. Case series, case reports and studies with $N<10$ were excluded due to limited generalizability.

\section{Search Strategy}

A search of electronic databases PsychINFO (APA), Scopus (Elsevier), Ovid Medline (US National Library of Medicine), Cochrane Collaboration's Central Register of Controlled Trials (CENTRAL; Cochrane), and Web of Science Core Collection (Clarivate Analytics) was conducted between the 5th and 6th of May 2018. The databases were searched in a multi-field format with search terms combined with Boolean logic and searched by keyword in order to capture a greater number of studies than would be gathered with a title search (see Table 1 for search terms utilized). Ancestry searches were utilized to search the reference lists of papers found, as well as searches of other studies citing these papers to identify additional studies that met the research criteria. Studies collected were screened to remove duplicates, and then screened by title and then abstract to exclude studies that did not meet the eligibility criteria. The remaining full-text papers were assessed for eligibility by an independent reviewer (U.M.); ambiguities between reviewers were resolved through discussion; after which $100 \%$ agreement was reached.

\section{Assessment of Methodological Quality}

Methodological quality and risk of bias of selected studies were assessed using the Cochrane Collaboration's tool for assessing risk of bias in randomized trails (Higgins and Green 2011), and the Risk of Bias in Non-randomized Studies-of Interventions (ROBINS-I, Sterne et al. 2016), which allowed sources of risk to be assessed, including allocation sequence and concealment, participant selection, blinding of participants, personnel and outcome assessors, deviations from intended intervention, incomplete outcome data, and selective reporting.

\section{Data Extraction}

Data extracted from the included studies were recorded using an extraction form developed for this review. It included study details (author, year, title, country), setting (e.g. clinical, community, school), recruitment method, targeted mental illness and standardized measures, intervention details (e.g. the length/dose of treatment), inclusion and exclusion criteria, study sample size, population demographics, and information to assess methodological quality and risk of bias.

\section{Data Synthesis}

The review used a systematic synthesis of results. Information is presented in text and tables to both summarize and explain characteristics of the included studies.

\section{Results}

\section{Study Selection}

A total of 1406 records were identified through database searches, and an additional 12 through manual and ancestry searches (total $\mathrm{N}=1418$ ). After removing 274 duplicates, screening by title removed 1107 records, and screening by abstract removed 23 records. The full texts of the remaining 14 records were reviewed. Of these papers, 11 were primary research studies and 2 were secondary research studies (neither of which presented further data on the primary study and thus were excluded from further analysis); 2 studies were conducted on an adult population, and 1 outlined a protocol for a transgender-affirmative CBT but included

Table 1 Search terms for electronic database search

\begin{tabular}{|c|c|}
\hline Key word & Search terms \\
\hline Mental illness & $\begin{array}{l}\text { Suicid* OR intentional self harm OR ISH OR Deliberate self harm* OR DSH OR Self injurious behav* OR Self injurious } \\
\text { behav* OR Self mutilat* OR self Injury OR Self destructive behav* OR Parasuicide OR Self poison* OR Self cutt* OR Non- } \\
\text { suicidal self injury OR NSSI OR self harm) AND (Depres* OR Anxi* OR Mental disorder* OR Mood disorder* OR Psycho- } \\
\text { logical Stress* OR Eating disorder* OR Psychiatric illness OR Psychiatric diagnosis OR Bipolar OR Schizophrenia OR Panic } \\
\text { OR Post-traumatic stress disorder OR PTSD OR Obsessive Compulsive Disorder OR OCD OR Personality disorder }\end{array}$ \\
\hline Youth & Child* OR Adolescent* OR Youth OR Teenager OR School-aged OR Student \\
\hline LGBTQIA & $\begin{array}{l}\text { Lesbian OR Gay OR Bisexual OR Trans* OR Queer OR Intersex OR Asexual OR Homosexual OR Gender dysphoria OR } \\
\text { Gender Minority OR Non-heterosexual OR Sister girl OR Brother boy }\end{array}$ \\
\hline Treatment & $\begin{array}{l}\text { Psychol* OR Treatment OR psychotherapy OR cognitive behav* therapy OR CBT OR dialectical behav* therapy OR DBT OR } \\
\text { acceptance commitment therapy OR ACT OR mindfulness OR MBCT OR MBSR OR MiCBT OR schema OR interpersonal } \\
\text { psychotherapy OR IPT OR narrative OR family OR solution focused brief therapy OR SFBT OR psychodynamic }\end{array}$ \\
\hline
\end{tabular}


no empirical data. This lead to a final sample of 9 research studies. Figure 1 presents a flow chart of the PRISMA study selection process; and Table 2 summarizes the main characteristics of the retained research studies.

\section{Study Characteristics}

\section{Population and Sample Demographics}

Nine studies with a total of 1149 participants were included. There was an equal representation of males and females in two studies (percentage of females 47.6-56.3), females were overrepresented in four studies (percentage of females ranged from 57 to 80), males were overrepresented in two studies (percentage of males ranged from 63.6 to 100 ), and non-binary participants were overrepresented in one study (percentage 75\%, however participants could select more than one gender identity). Regarding gender identity, four studies included transgender participants, and two studies included participants who identified as non-binary or two-spirit (a Native American term of gender variance). In regard to sexual orientation, one study included only gay male participants, two did not list specific sexuality data, there was an over representation of homosexual participants in three studies (percentage of lesbian/gay participants 36-60.1), and an over-representation of bisexual participants in one study (percentage of bisexual participants 70). Four studies also included participants who identified as queer, pansexual (attraction to any sex or gender), polysexual (attraction to multiple genders), and unsure/questioning (percentage of these participants ranged from 2 to 29). The mean
Fig. 1 PRISMA flow chart depicting study selection

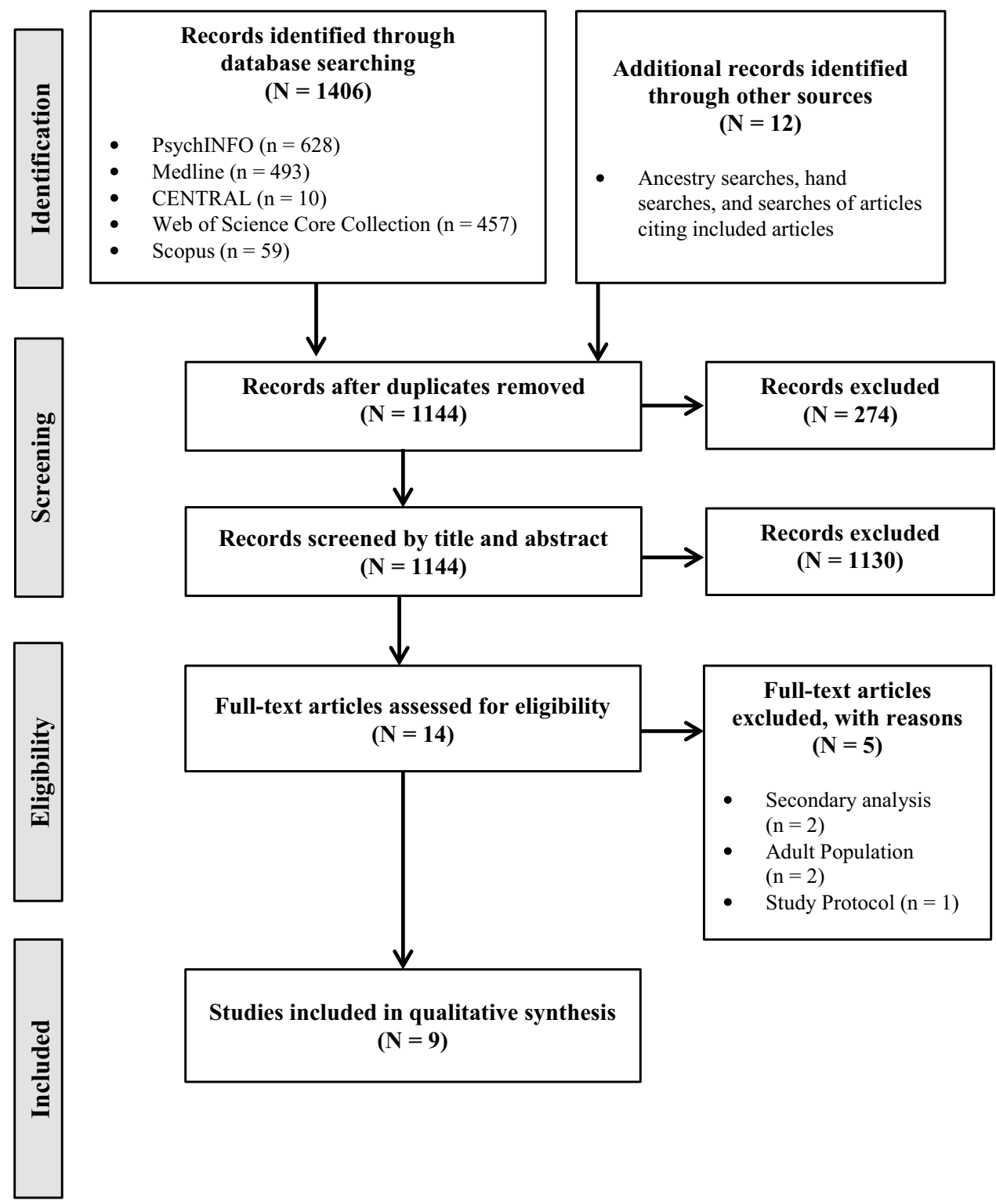




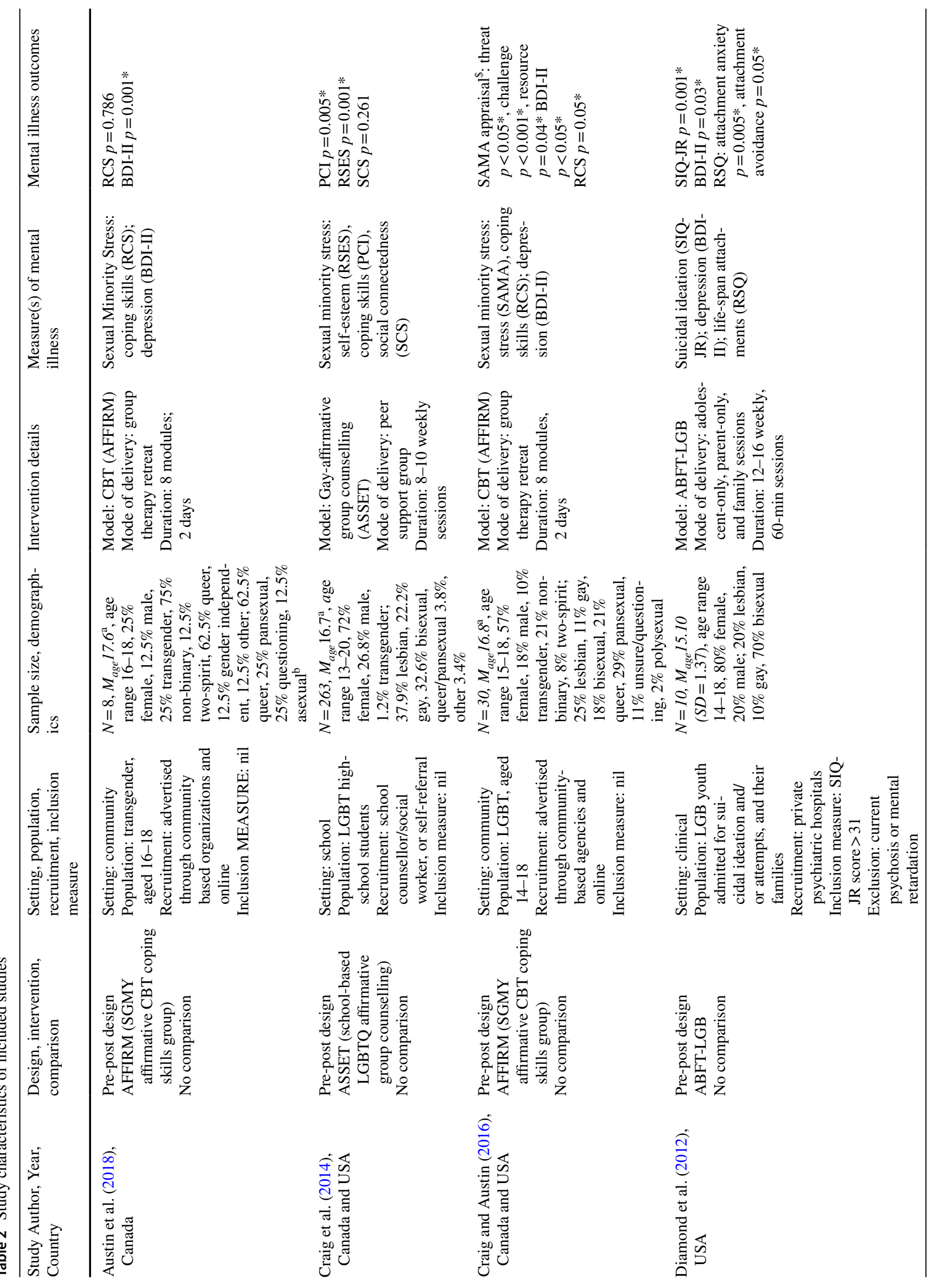




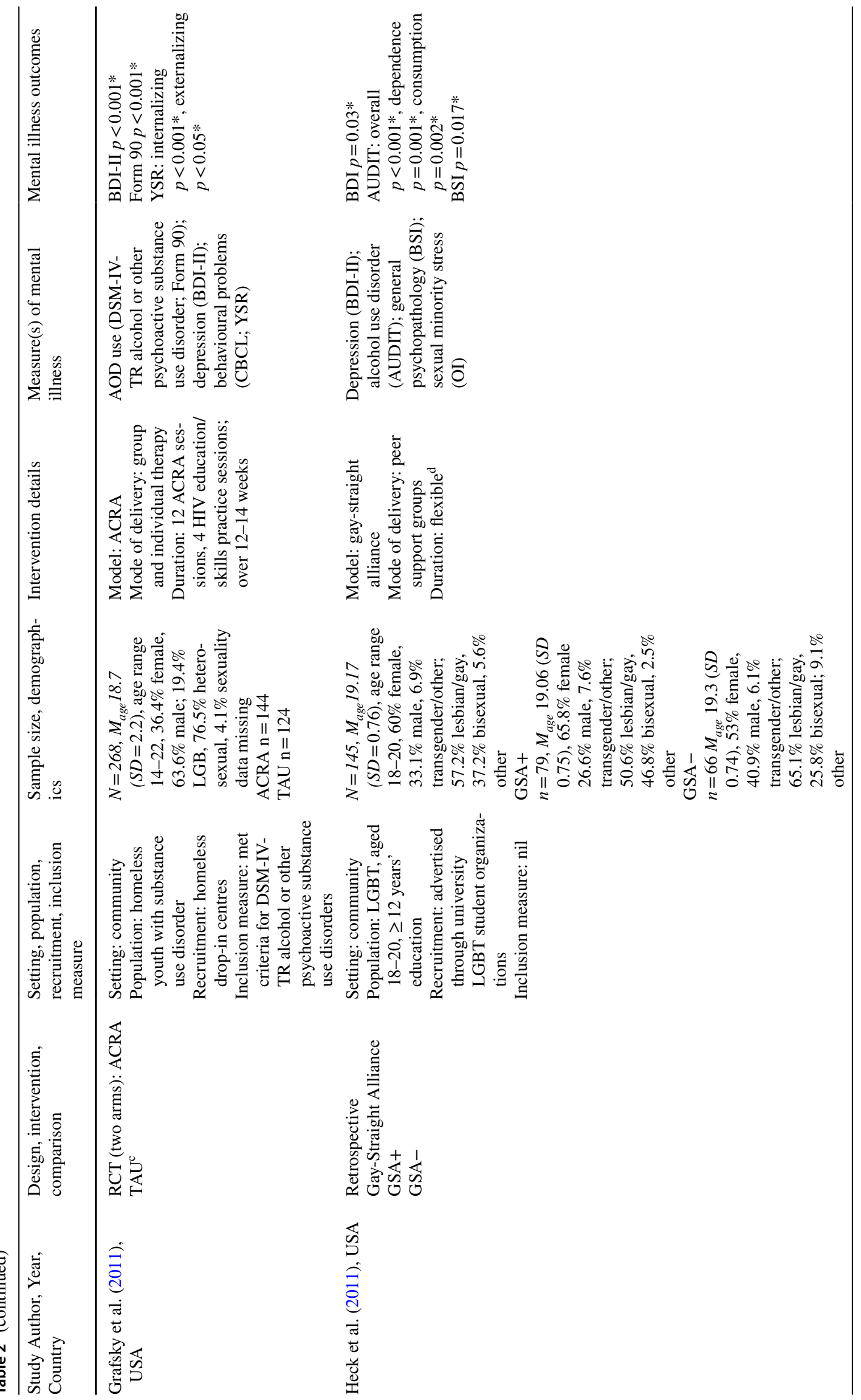




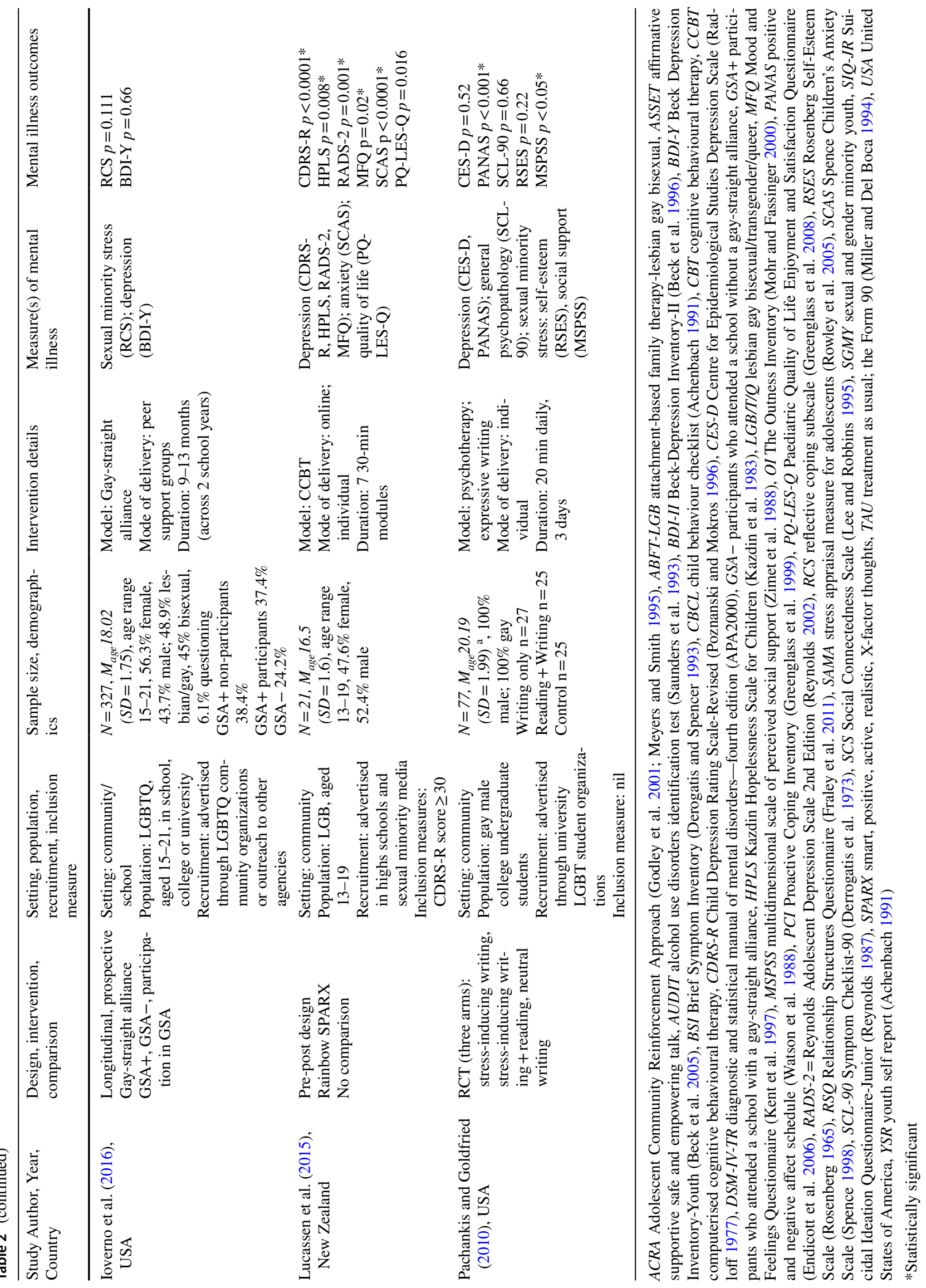


age of participants included in this review was 17.6 years ( $S D=1.61)$, the age range was $13-22$ years. The majority of examined studies recruited their participants from the community $(n=8)$, by means of advertisement $(n=6)$, referral from school counselors $(n=1)$, or approaching adolescents outside of community centers $(n=1)$, with one study recruiting from a clinical sample $(n=1)$. Additionally, studies were conducted across three different countries: Canada and the USA $(n=2)$, the USA $(n=5)$, Canada $(n=1)$ and New Zealand $(n=1)$. The psychological disorders and psychosocial issues targeted by the interventions were depression $(n=7)$, sexual minority stress $(n=5)$, alcohol use disorder $(n=2)$, suicidal ideation $(n=1)$, anxiety $(n=1)$, and behavioral problems $(n=1)$.

\section{Inclusion and Exclusion Criteria}

Eight studies required participants to identify as LGBTQIA, one required youth to be homeless, within which a subset identified as LGB. Three studies had specific age limits for inclusion, three required participants to be students (high school $n=1$, college $n=1$; high school, college, or university $n=1$ ), and one study required participants to have completed 12 or more years of education. Three studies required participants met clinical symptomatology on standardized instruments (suicidal ideation $n=1$, alcohol use disorder $n=1$, depression $n=1$ ). One study excluded participants with active psychosis or mental retardation.

\section{Study Design and Intervention Characteristics}

The majority of studies $(n=5)$ used a pre-post research design without a comparison group, two studies used an RCT design with comparison groups $(n=1 \mathrm{TAU}, n=1$ control), one used a longitudinal design, and one used a retrospective research design. Interventions were based on CBT $(n=3)$, Attachment-Based Family Therapy $(n=1)$, group counseling/peer support $(n=3)$, expressive writing $(n=1)$, or an Adolescent Community Reinforcement Approach $(n=1)$. One intervention was delivered online, and eight in person. Participants had between 2 days and 16 weeks to complete the treatment ( 2 days: $n=2,3$ days: $n=1,7$ weeks: $n=1,8-10$ weeks: $n=1,12-14$ weeks: $n=1,12-16$ weeks: $n=1$, unspecified $n=1$ ). Seven major treatment components were identified within studies, these being incorporating problem solving and/or coping skills training $(n=6)$, creating safe, supportive spaces $(n=4)$, discussion of shared experiences of bullying, rejection, harassment etc. $(n=5)$, drug counseling $(n=1)$, social skills training or family components (e.g. communication skills, assertiveness; $n=4$ ), and expressive writing $(n=1)$. 


\section{Mental Health Measurement}

There was a high degree of variability in which mental health was measured, according to the mental health disorders and psychosocial issues being addressed. Depression was measured using the Beck Depression Inventory-II [BDIII, Beck et al. (1996); $n=3$ ], Beck Depression InventoryYouth [BDI-Y, Beck et al. (2005); $n=1$ ], Child Depression Rating Scale-Revised [CDRS-R, Poznanski and Mokros (1996); $n=1$ ], Kazdin Hopelessness Scale for Children [HPLS, Kazdin et al. (1983); $n=1$ ], Reynolds Adolescent Depression Scale 2nd Edition [RADS-2, Reynolds (2002); $n=1$ ], Mood and Feelings Questionnaire [MFQ, Kent et al. (1997); $n=1]$, Centre for Epidemiological Studies Depression Scale [CES-D, Radloff (1977); $n=1$ ], and the positive and negative affect schedule [PANAS, Watson et al. (1988); $n=1]$. Sexual minority stress was measured with the Rosenberg Self-Esteem Scale [RSES, Rosenberg (1965); $n=2$ ], Proactive Coping Inventory [PCI, Greenglass et al. (1999); $n=1$ ], Social Connectedness Scale [SCS, Lee and Robbins (1995); $n=1]$, Stress Appraisal Measure for Adolescents [SAMA, Rowley et al. (2005); $n=1$ ], reflective coping subscale [RCS, Greenglass et al. (2008); $n=1$ ], and the Outness Inventory [OI, Mohr and Fassinger (2000); $n=1$ ]. Alcohol and other substance use was measured with the DSM IV-TR criteria for [Alcohol and other Psychoactive Substance Use Disorder (APA2000); $n=1$ ], The National Institute on Alcohol Abuse and Alcoholism's Form 90 [Miller and Del Boca (1994); $n=1]$, and the Alcohol Use Disorders Identification Test [AUDIT, Saunders et al. (1993); $n=1$ ]. Suicidal ideation was measured using the Suicidal Ideation Questionnaire-Junior [SIQ-JR, Reynolds (1987); $n=1$ ]. Anxiety was measured with the Spence Children's Anxiety Scale [SCAS, Spence (1998); $n=1]$. Behavioural problems were measured using the Child Behaviour Checklist and the Youth Self Report [CBCL, YSR, Achenbach (1991); $n=1$ ]. General psychological symptomology was measured with the Brief Symptom Inventory [BSI, Derogatis and Spencer (1993); $n=1$ ], Paediatric Quality of Life Enjoyment and Satisfaction Questionnaire Life [PQ-LES-Q, Endicott et al. (2006); $n=1]$ and the Symptom Cheklist-90 [SCL-90, Derogatis and Spencer (1993); $n=1]$.

\section{Mental Health Outcomes}

Overall, impacts on mental health varied considerably among the included studies and with measures used. When mental health was measured in terms of depression $(n=8)$, effects of interventions ranged from $p<0.0001$ to $p=0.66$. Alternatively, when mental health was measured in terms of sexual minority stress $(n=5)$, effects of interventions ranged from $p<0.001$ to $p=0.786$. When measured in regard to AOD use $(n=2)$, improvements were less variable, and significant across studies ranging from $p<0.001$ to $p=0.002$. Mental health was measured in relation to suicidal ideation in one study $(n=1)$, and intervention effects were significant at $p=0.001$. Anxiety was used as a measure of mental wellbeing in another study $(n=1)$, with significant effects $p<0.0001$. One study $(n=1)$ used behavioral problems as a measure of mental health, with effects ranging from $p<0.05$ to $p<0.001$. When general psychological symptomology and quality of life were used to measure mental wellbeing $(n=3)$, effects of interventions ranged from $p=0.66$ to $p=0.017$.

\section{Quality Assessment Within- and Across-Studies}

The methodological quality of the chosen papers varied, all but two studies rated as high risk on at least one domain on the Cochrane Collaboration Risk of Bias tool for randomized controlled trials (Higgins and Green 2011), or as moderate on the ROBINS-I assessment tool for non-randomized trials (Sterne et al. 2016). Overall, risk of bias across most studies was rated as low, however two studies were assessed to have moderate to high risk of bias, such that bias was judged as being sufficient to affect interpretation of results. See Table 3 for a summary of these results.

\section{Outcomes}

\section{Primary Outcome: Effect on Mental Health Due to the Treatment Components}

Affirmative-Based Intervention Craig et al. (2014) explored the effect of a gay-affirmative school peer group-counseling program on minority stress in LGBTQ high school students. Participants $(N=263)$ completed an $8-10$ week Affirmative Supportive Safe and Empowering Talk [ASSET; Craig (2013)] program focused on creating a safe, supportive environment, enhancing coping in family, school, general and mental health domains, discussion of shared experiences (e.g. bullying, familial rejection, coming out), developing problem solving and coping skills, and exploring familial and social relationships as sources of support. The study found that the ASSET program increased proactive coping and self-esteem. No significant increases in social connectedness were observed. Qualitative results indicate that participants found the intervention helpful. Craig and Austin (2016) and Austin et al. (2018) explored the effects of a gayaffirmative CBT coping skills retreat on minority stress and depression. Participants $(N=30$, and $N=8$, respectively) completed a 2-day retreat incorporating a manualised CBT intervention, AFFIRM, which focused on core CBT skills (e.g. psychoeducation, identifying and challenging cognitive distortions, assertiveness, coping skills and goal setting), enhancing peer support, and discussing impacts of homo- 


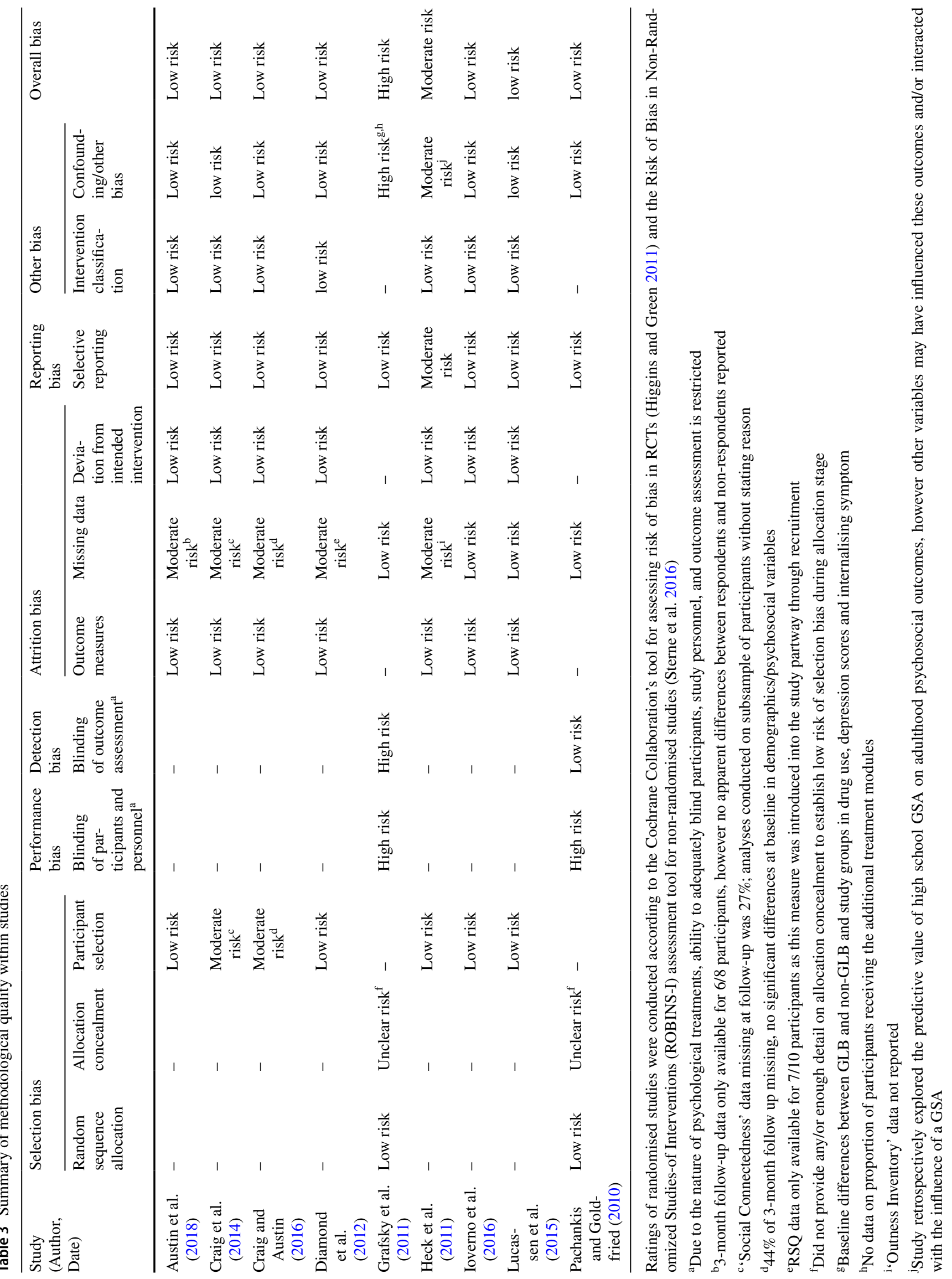


phobia and discrimination. Results of the first study founds that the AFFIRM program yielded significant decreases in depression (decreased from moderate to borderline clinical depression) and threat appraisal, and increased reflective coping from baseline to 3-month follow up. Challenge appraisal and resource appraisal increased significantly over the intervention period but these gains were not maintained at follow-up. The second AFFIRM study recruited only transgender youth, and found significant decreases in depression from baseline to 3-month follow up, although depression scores remained within the severe range. No significant increases in reflective coping were found. Qualitative results of both AFFIRM studies indicate that participants felt they benefited from the intervention.

Attachment-Based Family Therapy Diamond et al. (2012) explored the effects of LGB-tailored attachment-based family therapy (ABFT-LGB) on suicidality, depression and attachment in LGB youth. Participants $(N=10)$ completed a 12-16-week family-based therapy focused on strengthening relationships, reducing parental criticism, hostility and distress, enhancing communication, problem solving, affect regulation skills, promoting self-esteem and autonomy, and helping parents explore their feelings of disappointment, shame, anger and fear about sexuality. Up to five sessions were necessary for parents to explore these feelings. The study found that the intervention lead to significant decreases in suicidal ideation, depressive symptoms, and attachment anxiety and avoidance (the latter two variables significant after removing participants for whom only partial data were available due to attrition).

Computerized CBT Lucassen et al. (2015) explored the effects of a computerized CBT fantasy computer game tailored for sexual minority youth on depression, anxiety and quality of life. Participants $(N=21)$ completed the 7 part Rainbow SPARX intervention (i.e., tailored version of the SPARX program-Smart, Positive, Active, Realistic, X-factor thoughts) focusing on core CBT skills (e.g. psychoeducation, behavioral activation, identifying and challenging cognitive distortions, cognitive restructuring, communication skills, relaxation and mindfulness training, problem solving, and social skills training), and addressing challenges of bullying, homophobia, 'coming out' and societal assumptions of sexuality. The study found that the intervention lead to significant decreases in depressive symptoms, anxiety and hopelessness. No significant changes in quality of life were found. Qualitative results indicate the participants found the intervention useful.

Gay-Straight Alliances Heck et al. (2011) retrospectively explored the effects of attending a high school with a GayStraight Alliance (GSA) on depression and alcohol use disorders at college-age. Participants $(N=145)$ had either attended a school with a GSA $(n=79)$, or one without $(n=66)$. GSAs are student-led peer support groups that focus on creating safe, accepting school spaces for LGBT youth. The study found that participants who had attended schools with GSAs had significantly lower levels of depressive symptoms, alcohol use problems, dependence and consumption, and overall psychological symptomatology. Ioverno et al. (2016) prospectively explored the effects of attending a high school, university or college with a GSA, and whether or not individuals participated in these groups. Participants $(N=327)$ were tracked over two schooling years, with $24.2 \%$ attending a school without a GSA, $38.4 \%$ attended schools with GSAs but were not members, and $37.4 \%$ participated in their schools' GSAs. The study found that the presence of a GSA was associated with fewer experiences of homophobic bullying the following year, regardless of participation; and GSA presence and participation improved perceived safety. No changes over time were observed in depression or self esteem.

Adolescent Community Reinforcement Grafsky et al. (2011) explored the effects of an adolescent community reinforcement approach (ACRA) on alcohol and substance use, depression and behavioral problems in a community sample of homeless youth, both LGB and non-LGB. Participants $(\mathrm{N}=268)$ were randomly assigned to one of two groups: a $12-14$-week intervention $(n=144)$, or treatment as usual $(n=124)$. The ACRA intervention involved group and individual therapy focusing on problem solving, assertiveness and communication skills, decision making, functional analysis of drug-use behaviors and prosocial behaviors, relapse prevention, and HIV/AIDS education. Optional treatment included modules on affect regulation, assertiveness and relaxation training. The study found significant reductions in depression, illicit drug use, and internalizing symptoms across groups.

Expressive Writing Pachankis and Goldfried (2010) explored the effects of expressive writing about sexual minority stress on depression, self-esteem, and general psychopathology. Participants $(\mathrm{N}=77)$ were randomly allocated to one of three groups: writing over 3 days about their most stressful or traumatic gay-related event $(n=27)$, writing about such an event and reading their writing from the previous day $(n=25)$, or writing about a neutral topic $(n=25)$. The study found no significant differences between the two experimental groups. Participants in the experimental groups experienced significantly higher positive affect than the control group the day following the intervention, and were more open about their sexuality at 3-month follow up. No significant effects of depression, self-esteem or general psychopathology were found. 
Secondary Outcome: Individual Characteristics Associated with Treatment Efficacy

Sexuality, Gender Identity, Age, Race and Ethnicity Craig et al. (2014) reported no differences between participants of varied gender, sexual orientation, race or ethnicity in changes in proactive coping, self-esteem or social connectedness. Grafsky et al. (2011) found that LGB participants had significantly greater improvements in depression, illicit drug use, and internalizing symptoms than non-LGB participants. Ioverno et al. (2016) found that overall, young women and black youth reported lower levels of depression and higher levels of self esteem, and older participants reported higher self esteem. Craig and Austin (2016), Austin et al. (2018), Diamond et al. (2012), Heck et al. (2011), Lucassen et al. (2015), and Pachankis and Goldfried (2010) did not analyze differences in outcomes across demographic variables.

Baseline Symptom Severity Craig et al. (2014) reported poorer baseline levels of proactive coping for Hispanic lesbians than other minority groups. Grafsky et al. (2011) found that LGB youth had significantly greater depressive symptoms and internalizing symptoms than nonLGB youth. Pachankis and Goldfried (2010) found that participants assigned to the intervention group with lower baseline social support reported greater improvements in depression, psychological symptoms, and higher proportions of gay friends at 3-month follow-up. Interventions that required clinically significant baseline symptomatology for inclusion resulted in mental health improvements of a greater magnitude than studies conducted with participants who did not necessarily have poor baseline mental health (Diamond et al. 2012; Lucassen et al. 2015).

\section{Discussion}

LGBTQIA individuals in adolescence and emerging adulthood have higher rates of mental illness, suicidal ideation and suicide attempts then their non-LGBTQIA peers. Specific risk factors such as harassment and abuse, low self-esteem, and challenges in peer- and parental-acceptance, have been identified as particularly relevant to sexual minority youth. Despite evidence for the impact of these risk factors on negative psychological and physical outcomes, there is no research pooling evidence on how treatments can effectively target these unique risk factors. The current systematic review explored how treatments can be tailored to these needs.

\section{Summary of Main Findings}

The primary aim of the current study was to systematically review existing literature on psychological and psychosocial interventions for LGBTQIA youth aged 12-25, in order to ascertain whether certain treatment components consistently show greater efficacy/effectiveness over others. A secondary aim was to review individual characteristics related to treatment outcomes. Nine studies [two randomized controlled trials (RCTs), five pre-post designs, one retrospective study, one longitudinal study] were identified with a total of 814 participants; across three countries; addressing depression, suicidality, sexual minority stress, anxiety, alcohol and substance use disorders, behavioral problems, general psychopathology and quality of life.

Results were interpreted in regard to delivery mode, participants, theoretical orientation, and program components. Outcomes were similar across both individual and group delivery modes, and with participants being individuals or families. Employing cognitive behavioral therapy (CBT) as the main theoretical orientation was successful in reducing depressive and anxious symptoms within community groups, while attachment-based family therapy (ABFT) and adolescent community reinforcement approach (ACRA) orientations successfully did this within clinical and vulnerable community (i.e., homeless) populations, respectively (Austin et al. 2018; Craig and Austin 2016; Diamond et al. 2012; Grafsky et al. 2011; Lucassen et al. 2015). Specifically, the three studies employing CBT produced outcomes of decreased depression, hopelessness, anxiety, sexual minority stress, coping skills, and were found to be helpful (Austin et al. 2018; Craig and Austin 2016; Lucassen et al. 2015). Interestingly, the AFFIRM study with LGBTQ youth generally yielded improvements in coping skills that were not replicated with a transgender youth population. This may be reflective of the increased stressors experienced by transgender youth, and of the overall higher depressive scores post-intervention in the transgender group (Austin et al. 2018; Craig and Austin 2016). When gay-affirmative practice was the orientation, improvements in coping, selfesteem and depressive symptoms were observed (Craig et al. 2014; Heck et al. 2011). A psychotherapy approach returned the least change with no effects reported on depression or self-esteem (Pachankis and Goldfried 2010). Results show that program components of creating safe, supportive spaces as part of the therapeutic process were generally associated with improvements in depression, sexual minority stress, alcohol and other drug (AOD) use, general psychopathology and participant reports of interventions being helpful (Craig et al. 2014; Heck et al. 2011). Perhaps the positive effects of GSAs on depression and psychological wellbeing found in Heck et al. (2011)'s retrospective study but not confirmed in Ioverno et al. (2016)'s prospective study could be attributed 
to confounding factors in the former study. It is important to consider however, that improvements in experiences of bullying and safety would likely yield positive longer term effects on wellbeing. This supports the idea that targeting the unique needs of LGBTQIA youth, such as improving selfesteem, in-group and family acceptance, and reducing risk behaviors, can lead to positive outcomes. Similarly, incorporating discussion of shared experiences was associated with improvements in depression, anxiety, AOD use, behavioral problems, sexual minority stress, general psychopathology and participant helpfulness ratings (Craig and Austin 2016; Craig et al. 2014; Heck et al. 2011; Lucassen et al. 2015). Incorporating social, coping skills and/or decision making skills training (either independently or within the context of CBT) was associated with improved sexual minority stress (i.e., proactive and reflective coping, improved appraisal skills, increased self-esteem), decreased depressive symptoms, hopelessness, anxiety, suicidality, attachment anxiety and avoidance, drug use, psychological symptomatology, and internalizing and externalizing symptoms, and was found to be helpful by participants (Craig and Austin 2016; Craig et al. 2014; Diamond et al. 2012; Grafsky et al. 2011; Lucassen et al. 2015). The one study that employed drugspecific counseling tools was associated with significantly decreased drug use (Grafsky et al. 2011). While GSAs were associated with decreased alcohol use problems without directly targeting this, this result should be interpreted with caution due to retrospective nature of this study and thus the likely presence of other confounding factors (Heck et al. 2011). Of approaches explored, expressive writing was perhaps the least effective, with no significant changes reported in depression, self-esteem or general psychopathology, and an initially increased positive affect not maintained at follow up. Importantly, greater openness about sexuality was reported at follow up (Pachankis and Goldfried 2010).

Results related to the secondary aim indicated that LGBTQIA youth often had poorer mental health at baseline and experienced greater improvements than non-LGBTQIA youth. For example, one study found that lesbian, gay and bisexual (LGB) youth had greater levels of depressive symptoms and internalizing behaviors at baseline than non-LGB youth, and experienced greater improvements such that symptom severity was more equivalent post-intervention. LGB participants also experienced greater decreases in illicit drug use (Grafsky et al. 2011). Another study found that Hispanic participants identifying as lesbian had significantly poorer proactive coping skills at baseline than other minority groups, which particularly highlights the relevance of minority stress theory when applied to youth belonging to multiple minority groups (Craig et al. 2014). One further study found that gay males with lower baseline social support experienced greater improvements in depressive symptoms, social support and overall psychopathology when allocated to the experimental rather than the control group (Pachankis and Goldfried 2010). This may suggest that these symptoms can improve without being targeted directly, however this should be interpreted with caution, as improvements were not significant overall.

\section{Experimental Manipulations of Treatment-Related Variables Associated with Improved Mental Health}

Considering the critical impact that parental acceptance and attachment plays on suicidality, mental and physical health, and healthy adult relationships, it is likely that including family therapy components such as in Diamond et al. (2012) could vastly improve treatment outcomes for youth still in the care of their parents (Katz-Wise et al. 2016; Ryan et al. 2009; Yadegarfard et al. 2014). It is interesting that despite previous findings that parental support is more protective than social support (McConnell et al. 2016; Watson et al. 2016), every intervention reviewed that included social skills training or a social component resulted in significant decreases in depressive symptoms (Craig et al. 2014; Grafsky et al. 2011; Lucassen et al. 2015).

It is unsurprising that treatments conducted in accordance with minority stress theory were effective in reducing depressive and stress symptoms and enhancing coping and appraisal skills. Interestingly, the studies that did not use empirically based treatment still yielded improvements via the use of gay-affirmative counseling, creating safe spaces, open discussion of unique experiences, coping, social, and cognitive appraisal skills training. Further, it was found that even studies that did not explicitly target depressive symptoms, were found to have positive influences on these symptoms (Grafsky et al. 2011; Heck et al. 2011). This supports previous evidence of these as being critical in targeting minority stress, and the concept of using social supports to re-appraise threat and self-efficacy (Alessi 2014; Kertzner 2001; Meyer 2003).

Findings of the current review are in accordance with findings from the ESTEEM gay-affirmative CBT program that incorporating coping skills, cognitive restructuring, and promoting self-efficacy were able to reduce depression, alcohol abuse, and sexual compulsivity in gay and bisexual male participants (Pachankis et al. 2015). This is a useful finding as it suggests that treatments designed for use in adult populations are likely generalizable to younger people. Similarly, in support of previous findings with adults, LGBTQIA youth also found the teaching of coping and communication skills helpful (Israel et al. 2008).

\section{Individual Characteristics Associated with Treatment Efficacy/Effectiveness}

The findings of the current review consolidate evidence that LGBTQIA adolescents have poorer mental health than 
non-LGBTQIA adolescents. However the included studies did not explore within-group differences sufficiently to add to previous findings, for instance that bisexual females are at higher risk of self-harm or that lesbian females gain less benefit from parental support than females of other sexual orientations (Watson et al. 2016; Zaki et al. 2017), or that gender-minority men are more prone to depression and panic attacks, whereas females are more prone to GAD (Cochran et al. 2003).

\section{Limitations of the Research}

The research findings of studies included should be considered in the context of identified limitations. Of the nine studies reviewed, four were not necessarily psychological interventions, and another incorporated only one specific component of psychotherapy. While this is not necessarily a hindrance, as some produced positive findings, it is possible that more evidence-based treatments such as CBT would have yielded stronger positive outcomes. In terms of costefficiency, it is encouraging that four of the studies included were successfully able to yield positive changes within a group environment. In terms of clinical relevance and generalizability, only three of the included studies required a mental health diagnosis or significant impairment for inclusion, and thus while the other studies give interesting insight into intervention adaptations effective within community populations, it is important to explore the efficacy/effectiveness of these interventions when baseline symptoms are in the clinical range.

\section{Limitations of the Current Review}

The results of this review should be interpreted in the context of several limitations. Studies were only included if they were published in English; with unpublished studies, theses or other grey literature excluded. The results are all from first-world countries, thus the included samples may not be generalizable to global populations. The limited availability of research in the area and thus small sample of studies included may also impact generalizability of findings. Importantly, only two of the included studies were RCTs, and thus while interventions were found to be effective across many domains, this hasn't been established in comparison to other empirically supported interventions or control groups. Notably, the non-randomized trials have not yet been followed up with experimental designs to further test their findings, which would make interpretation of results more robust and reliable. Interestingly, while adolescents experience challenges and experiences unique to this particular life stage (e.g. puberty, periods of transitioning, the high school environment, identity development), perhaps including studies of mental health treatment for LGBTQIA adults could have provided further insights into specific treatment components and individual characteristics important in the therapeutic process and outcome.

\section{Future Research Directions}

In light of the limited research available on psychological interventions for LGBTQIA youth experiencing mental health difficulties, it is recommended that future research trial the implementation of treatment components found to be effective. Thus, where appropriate, incorporating components such as safe spaces, discussion of shared experiences, decision making, coping and social skills, and AOD counseling into the treatment of LGBTQIA youth diagnosed with mental illnesses may return benefit It is also suggested that treatment modalities may be adapted to the target population, as it was found that CBT was effective in work with individual youth and community groups, ACRA was beneficial in a community support setting, and ABFT was an effective family-based approach. Many of the interventions reviewed were not based on empirically supported modalities, however still found value in the creation of safe spaces and open discussion of shared challenges and supports. In the light of minority stress theory, it is suggested that future interventions be developed from evidence-based practices such as CBT or family-based therapies where indicated, with the critical incorporation of gay-affirmative practice such as creation of safe spaces and fostering discussion of shared experiences. This is especially important as adolescents have a high risk of suicide and treatments must be effective in targeting and preventing this (AIHW 2014). While certain treatment components such as expressive writing may be beneficial in certain aspects of minority stress, for example increasing openness about one's sexuality, treatments cannot ethically rely solely on these individual treatment components without empirical evidence that they significantly decrease mental ill-health and suicide risk. Ideally, amalgamating these therapeutic components and applying them in an RCT compared with standardized CBT, waitlist control, or TAU would yield helpful insight into the efficacy of these treatment adaptations.

\section{Conclusion}

There is significant evidence that LGBTQIA youth are more prone to mental illness and psychosocial stressors than the general population, with these factors generally not improving across the lifespan. This suggests that current treatment options are not adequately addressing unique characteristics of these youth. The current review has summarized available evidence on the unique needs 
of LGBTQIA adolescents, and the factors that positively influence treatment outcomes. In relation to the unique risk and protective factors experienced by LGBTQIA youth, it is evident that treatments must target self-esteem, peer and parental acceptance, risk behaviors, and experiences of harassment and abuse both within school and home environments. It can be seen that these needs are particularly relevant to this developmental period wherein youth are strongly influenced by school peers, their parents, exploring risky behaviors, and developing self-identity and esteem. In accordance with these unique developmental needs, the review found that factors such as creating safe spaces, facilitating discussion of shared experiences of victimization, opening familial discussion around homosexuality, bullying, homophobia and coming out, teaching social, coping and decision making skills, and conducting AOD counseling where relevant, may influence the effectiveness of treatment. Findings relating to minimizing the impacts of victimization and harassment are especially relevant to the exploration of adolescent development as these variables have been strongly linked to attempted suicide (AIHW 2014). In regard to modalities, CBT and ABFT were found to be effective therapeutic frameworks with LGBTQIA youth. This is unsurprising looking at the enduring importance of family acceptance and connectedness during adolescent development on psychological and physical wellbeing (NLHA 2016). However, caution must be taken when generalizing these findings. As indicated by this review, these findings have not been replicated in further RCTs for LGBTQIA youth experiencing mental illness. Additionally, due to the limited number of available studies, the influence of individual-related variables such as age, sexual orientation, gender identity, or symptom severity, on treatment outcomes were not able to be rigorously explored. Nevertheless, preliminary evidence was found to explain some specific therapeutic components required to target the unique needs of LGBTQIA youth, and found that tailoring treatments can yield benefits in mental health despite poorer baseline mental health. Further research is strongly suggested to further explore these treatment components within clinical populations wherein intervention is most vital, and to further assess the association between individual characteristics and treatment outcome.

Author contributions EVDPH conceived of the study, participated in the design and coordination of the study, conducted the review and interpretation of the data, and drafted the manuscript; UM was the second reviewer in the full-text review process; JM participated in conceiving the study, its design, coordination and interpretation, and helped draft the manuscript. All authors read and approved the final manuscript.
Funding This research received no specific grant from any funding agency in the public, commercial, or not-for-profit sectors.

\section{Compliance with ethical standards}

Conflict of interest The authors report no conflict of interest.

\section{References}

Achenbach, T. M. (1991). Integrative guide for the 1991 CBCL/4-18, $Y S R$, and TRF profiles. Burlington: Department of Psychiatry, University of Vermont.

Alessi, E. J. (2014). A framework for incorporating minority stress theory into treatment with sexual minority clients. Journal of Gay \& Lesbian Mental Health, 18(1), 47-66.

American Psychiatric Association. (1994). Diagnostic and statistical manual of mental disorders (4th ed.). Washington, DC: APA DSM-IV.

American Psychiatric Association. (2000). Diagnostic and statistical manual of mental disorders (4th ed.). Washington, DC: APA DSM-IV-TR.

Asscheman, H., Giltay, E. J., Megens, J. A., de Ronde, W., Van Trotsenburg, M., \& Gooren, L. J. (2011). A long-term follow-up study of mortality in transsexuals receiving treatment with cross-sex hormones. European Journal of Endocrinology, 164(4), 635-642.

Austin, A., Craig, S. L., \& D'Souza, S. A. (2018). An AFFIRMative cognitive behavioral intervention for transgender youth: preliminary effectiveness. Professional Psychology-Research and Practice, 49(1), 1-8. https://doi.org/10.1037/pro0000154.

Australian Bureau of Statistics. (2007). National survey of mental health and wellbeing (No.4235.0). Canberra: ACT.

Australian Institute of Health and Welfare. (2014). Leading causes of death by sex and age group, 2012-2014. https://www.aihw.gov.au/ reports/life-expectancy-death/deaths-in-australia/data. Accessed 3 Jan 2018.

Beck, A. T., Steer, R. A., \& Brown, G. K. (1996). Beck depression inventory-II. San Antonio, TX: The Psychological Corporation.

Beck, J. S., Beck, A. T., Jolly, J. B., \& Steer, R. A. (2005). Beck youth inventories: For children and adolescents. San Antonia: Psychological Corporation.

Birkett, M., Espelage, D. L., \& Koenig, B. (2009). LGB and questioning students in schools: The moderating effects of homophobic bullying and school climate on negative outcomes. Journal of Youth and Adolescence, 38(7), 989-1000.

Bontempo, D. E., \& D’Augelli, A. R. (2002). Effects of at-school victimization and sexual orientation on lesbian, gay, or bisexual youths' health risk behavior. Journal of Adolescent Health, 30(5), 364-374.

Centers for Disease Control and Prevention. (2012). Youth risk behaviour surveillance-United States, 2011. Morbidity and Mortality Weekly Report, 61(4), 11-12.

Cochran, S. D., Sullivan, J. G., \& Mays, V. M. (2003). Prevalence of mental disorders, psychological distress, and mental health services use among lesbian, gay, and bisexual adults in the United States. Journal of Consulting and Clinical Psychology, 71(1), 53.

Connolly, M. D., Zervos, M. J., Barone, C. J., Johnson, C. C., \& Joseph, C. L. (2016). The mental health of transgender youth: Advances in understanding. Journal of Adolescent Health, 59(5), 489-495.

Craig, S. L. (2013). Affirmative supportive safe and empowering talk (ASSET): Leveraging the strengths and resiliencies of sexual minority youth in school-based groups. Journal of LGBT Issues in Counseling, 7(4), 372-386. 
Craig, S. L., \& Austin, A. (2016). The AFFIRM open pilot feasibility study: A brief affirmative cognitive behavioral coping skills group intervention for sexual and gender minority youth. Children and Youth Services Review, 64, 136-144.

Craig, S. L., Austin, A., \& McInroy, L. B. (2014). School-based groups to support multiethnic sexual minority youth resiliency: Preliminary effectiveness. Child and Adolescent Social Work Journal, 31(1), 87-106.

D'augelli, A. R. (2002). Mental health problems among lesbian, gay, and bisexual youths ages 14 to 21. Clinical Child Psychology and Psychiatry, 7(3), 433-456.

D'Augelli, A. R. (2003). Lesbian and bisexual female youths aged 14 to 21: Developmental challenges and victimization experiences. Journal of Lesbian Studies, 7(4), 9-29.

De Vries, A. L., McGuire, J. K., Steensma, T. D., Wagenaar, E. C., Doreleijers, T. A., \& Cohen-Kettenis, P. T. (2014). Young adult psychological outcome after puberty suppression and gender reassignment. Pediatrics, 134(4), 696-704.

Derogatis, L. R., \& Spencer, P. (1993). Brief symptom inventory: BSI. Upper Saddle River, NJ: Pearson.

Derrogatis, L., Lipman, R., \& Covi, I. (1973). The SCL-90: An outpatient psychiatric rating scale. Psychopharmacology Bulletin, 9(1), 13-28.

Dhejne, C., Lichtenstein, P., Boman, M., Johansson, A. L., Långström, N., \& Landén, M. (2011). Long-term follow-up of transsexual persons undergoing sex reassignment surgery: Cohort study in Sweden. PLoS One, 6(2), e16885.

Diamond, G. M., Diamond, G. S., Levy, S., Closs, C., Ladipo, T., \& Siqueland, L. (2012). Attachment-based family therapy for suicidal lesbian, gay, and bisexual adolescents: A treatment development study and open trial with preliminary findings. Psychotherapy: Theory, Research, Practice, Training, 49(1), 62.

Eisenberg, M. E., \& Resnick, M. D. (2006). Suicidality among gay, lesbian and bisexual youth: The role of protective factors. Journal of Adolescent Health, 39(5), 662-668.

Endicott, J., Nee, J., Yang, R., \& Wohlberg, C. (2006). Pediatric quality of life enjoyment and satisfaction questionnaire (PQLES-Q): reliability and validity. Journal of the American Academy of Child \& Adolescent Psychiatry, 45(4), 401-407.

Fraley, R. C., Heffernan, M. E., Vicary, A. M., \& Brumbaugh, C. C. (2011). The experiences in close relationships-Relationship Structures Questionnaire: A method for assessing attachment orientations across relationships. Psychological Assessment, 23(3), 615

Gandhi, A., Luyckx, K., Maitra, S., \& Claes, L. (2015). Non-suicidal self-injury and identity distress in Flemish adolescents: Exploring gender differences and mediational pathways. Personality and Individual Differences, 82, 215-220.

Godley, S. H., Meyers, R. J., Smith, J. E., Karvinen, T., Titus, J. C., Godley, M. D., et al. (2001). The adolescent community reinforcement approach for adolescent cannabis users, Cannabis Youth Treatment (CYT) series (Vol. 4). Rockville, MD: Center for Substance Abuse Treatment, Substance Abuse and Mental Health Services Administration.

Grafsky, E. L., Letcher, A., Slesnick, N., \& Serovich, J. M. (2011). Comparison of treatment response among GLB and non-GLB street-living youth. Children and Youth Services Review, 33(5), 569-574. https://doi.org/10.1016/j.childyouth.2010.10.007.

Greenglass, E., Schwarzer, R., \& Laghi, F. (2008). The proactive coping inventory for adolescents. http://www.psych.yorku .ca/TheproactiveCopingInventoryFORADOLESCENTS.CA. Accessed 3 Jan 2018.

Greenglass, E., Schwarzer, R., \& Taubert, S. (1999). The proactive coping inventory (PCI): A multidimensional research instrument. Vyhledano, 3, 2011.
Haas, A. P., Rodgers, P. L., \& Herman, J. L. (2014). Suicide attempts among transgender and gender non-conforming adults. Work, 50, 59.

Hall, W. J. (2018). Psychosocial risk and protective factors for depression among lesbian, gay, bisexual, and queer youth: a systematic review. Journal of Homosexuality, 65(3), 263-316.

Heck, N. C., Flentje, A., \& Cochran, B. N. (2011). Offsetting risks: high school gay-straight alliances and lesbian, gay, bisexual, and transgender (LGBT) youth. School Psychology Quarterly, 26(2), 161-174. https://doi.org/10.1037/a0023226.

Heron, M. P. (2017). Deaths: Leading causes for 2015. National Vital Statistics Reports, 66(5), 1-76.

Higa, D., Hoppe, M. J., Lindhorst, T., Mincer, S., Beadnell, B., Morrison, D. M., \& Mountz, S. (2014). Negative and positive factors associated with the well-being of lesbian, gay, bisexual, transgender, queer, and questioning (LGBTQ) youth. Youth \& Society, 46(5), 663-687.

Higgins, J. P., \& Green, S. (2011). Cochrane handbook for systematic reviews of interventions (Vol. 4). Hoboken: Wiley.

Ioverno, S., Belser, A. B., Baiocco, R., Grossman, A. H., \& Russell, S. T. (2016). The protective role of gay-straight alliances for lesbian, gay, bisexual, and questioning students: A prospective analysis. Psychology of Sexual Orientation and Gender Diversity, 3(4), 397-406. https://doi.org/10.1037/sgd0000193.

Israel, T., Gorcheva, R., Burnes, T. R., \& Walther, W. A. (2008). Helpful and unhelpful therapy experiences of LGBT clients. Psychotherapy Research, 18(3), 294-305.

Justice, M. (2016). Social support and mental health among homeless youth: A multi-group SEM model of non-LGBT*, LGB, and Trans* Youth in Metro-Atlanta. Atlanta, GA: Georgia State University. (Unpublished master's thesis).

Kane, E. W. (2006). "No way my boys are going to be like that!" Parents' responses to children's gender nonconformity. Gender \& Society, 20(2), 149-176.

Katz-Wise, S. L., Rosario, M., \& Tsappis, M. (2016). LGBT youth and family acceptance. Pediatric Clinics of North America, 63(6), 1011.

Kazdin, A. E., French, N. H., Unis, A. S., Esveldt-Dawson, K., \& Sherick, R. B. (1983). Hopelessness, depression, and suicidal intent among psychiatrically disturbed inpatient children. Journal of Consulting and Clinical Psychology, 51(4), 504.

Kent, L., Vostanis, P., \& Feehan, C. (1997). Detection of major and minor depression in children and adolescents: Evaluation of the Mood and Feelings Questionnaire. Journal of Child Psychology and Psychiatry, 38(5), 565-573.

Kertzner, R. M. (2001). The adult life course and homosexual identity in midlife gay men. Annual Review of Sex Research, 12(1), 75-92.

King, M., Semlyen, J., Tai, S. S., Killaspy, H., Osborn, D., Popelyuk, D., \& Nazareth, I. (2008). A systematic review of mental disorder, suicide, and deliberate self harm in lesbian, gay and bisexual people. BMC Psychiatry, 8(1), 70.

Kuyper, L., \& Fokkema, T. (2011). Minority stress and mental health among Dutch LGBs: Examination of differences between sex and sexual orientation. Journal of Counseling Psychology, 58(2), 222.

Lee, R. M., \& Robbins, S. B. (1995). Measuring belongingness: The social connectedness and the social assurance scales. Journal of Counseling Psychology, 42(2), 232.

Leonard, W., Pitts, M., Mitchell, A., Lyons, A., Smith, A., Patel, S., \& Barrett, A. (2012). Private Lives 2: The second national survey of the health and wellbeing of gay, lesbian, bisexual and transgender (GLBT) Australians. Melbourne, VIC: The Australian Research Centre in Sex, Health \& Society, La Trobe University.

Levy, S. A., Russon, J., \& Diamond, G. M. (2016). Attachment-based family therapy for suicidal lesbian, gay, and bisexual adolescents: A case study. Australian and New Zealand Journal of Family Therapy, 37(2), 190-206. https://doi.org/10.1002/anzf.1151. 
Lowry, R., Johns, M., Robin, L., \& Kann, L. (2017). The effect of minority stress on substance use disparities among sexual minority US high school students. Journal of Adolescent Health, 60(2), S30-S31.

Lucassen, M. F. G., Merry, S. N., Hatcher, S., \& Frampton, C. M. A. (2015). Rainbow SPARX: A novel approach to addressing depression in sexual minority youth. Cognitive and Behavioral Practice, 22(2), 203-216.

McConnell, E. A., Birkett, M., \& Mustanski, B. (2016). Families matter: Social support and mental health trajectories among lesbian, gay, bisexual, and transgender youth. Journal of Adolescent Health, 59(6), 674-680.

McMahon, E. M., Keeley, H., Cannon, M., Arensman, E., Perry, I. J., Clarke, M., \& Corcoran, P. (2014). The iceberg of suicide and self-harm in Irish adolescents: A population-based study. Social Psychiatry and Psychiatric Epidemiology, 49(12), 1929-1935.

Mental Health Foundation. (2016). Fundamental facts about mental health 2016. London: Mental Health Foundation. https://www. mentalhealth.org.uk/sites/default/files/fundamental-facts-about -mental-health-2016.pdf. Accessed 21 Apr 2018.

Meyer, I. H. (2003). Prejudice, social stress, and mental health in lesbian, gay, and bisexual populations: Conceptual issues and research evidence. Psychological Bulletin, 129(5), 674.

Meyers, R. J., \& Smith, J. E. (1995). Clinical guide to alcohol treatment: The community reinforcement approach. New York, NY: Guildford Press.

Miller, W. R., \& Del Boca, F. K. (1994). Measurement of drinking behavior using the Form 90 family of instruments. Journal of Studies on Alcohol, Supplement(12), 112-118.

Moher, D., Liberati, A., Tetzlaff, J., Altman, D. G., \& The, P. G. (2009). Preferred reporting items for systematic reviews and meta-analyses: The PRISMA statement. PLoS Medicine, 6, e1000097.

Mohr, J., \& Fassinger, R. (2000). Measuring dimensions of lesbian and gay male experience. Measurement and Evaluation in Counseling and Development, 33(2), 66-66.

Mosher, W. D., Chandra, A., \& Jones, J. (2005). Sexual behavior and selected health measures: Men and women 15-44 years of age, United States, 2002. Hyattsville, MD: Advance Data from Vital and Health Statistics no. 362, National Centre for Health Statistics.

Murad, M. H., Elamin, M. B., Garcia, M. Z., Mullan, R. J., Murad, A., Erwin, P. J., \& Montori, V. M. (2010). Hormonal therapy and sex reassignment: A systematic review and meta-analysis of quality of life and psychosocial outcomes. Clinical Endocrinology, 72(2), 214-231.

National LGBTI Health Alliance. (2016). Snapshot of mental health and suicide prevention statistics for LGBTI people. Newtown, NSW: National LGBTI Health Alliance.

Needham, B. L., \& Austin, E. L. (2010). Sexual orientation, parental support, and health during the transition to young adulthood. Journal of Youth and Adolescence, 39(10), 1189-1198.

Newfield, E., Hart, S., Dibble, S., \& Kohler, L. (2006). Female-tomale transgender quality of life. Quality of Life Research, 15(9), $1447-1457$.

Olson, J., Schrager, S. M., Belzer, M., Simons, L. K., \& Clark, L. F. (2015). Baseline physiologic and psychosocial characteristics of transgender youth seeking care for gender dysphoria. Journal of Adolescent Health, 57(4), 374-380. https://doi.org/10.1016/j. jadohealth.2015.04.027.

Pachankis, J. E., \& Goldfried, M. R. (2010). Expressive writing for gay-related stress: Psychosocial benefits and mechanisms underlying improvement. Journal of Consulting and Clinical Psychology, 78(1), 98-110. https://doi.org/10.1037/a0017580.

Pachankis, J. E., Hatzenbuehler, M. L., Rendina, H. J., Safren, S. A., \& Parsons, J. T. (2015). LGB-affirmative cognitive-behavioral therapy for young adult gay and bisexual men: A randomized controlled trial of a transdiagnostic minority stress approach. Journal of Consulting and Clinical Psychology, 83(5), 875.

Padilla, Y. C., Crisp, C., \& Rew, D. L. (2010). Parental acceptance and illegal drug use among gay, lesbian, and bisexual adolescents: Results from a national survey. Social Work, 55(3), 265-275.

Peterson, C. M., Matthews, A., Copps-Smith, E., \& Conard, L. A. (2017). Suicidality, self-harm, and body dissatisfaction in transgender adolescents and emerging adults with gender dysphoria. Suicide and Life-Threatening Behavior, 47(4), 475-482.

Poznanski, E. O., \& Mokros, H. B. (1996). Children's depression rating scale, revised (CDRS-R). Los Angeles: Western Psychological Services.

Radloff, L. S. (1977). The CES-D scale: A self-report depression scale for research in the general population. Applied Psychological Measurement, 1(3), 385-401.

Reynolds, W. (2002). Manual for the Reynolds Adolescent Depression Scale-Second Edition (RADS-2). Lutz, FL: Psychological Assessment Resources.

Reynolds, W. M. (1987). Suicidal ideation questionnaire (SIQ). Odessa, FL: Psychological Assessment Resources.

Roberts, A. L., Rosario, M., Corliss, H. L., Koenen, K. C., \& Austin, S. B. (2012). Elevated risk of posttraumatic stress in sexual minority youths: Mediation by childhood abuse and gender nonconformity. American Journal of Public Health, 102(8), $1587-1593$.

Rosario, M., \& Schrimshaw, E. W. (2013). The sexual identity development and health of lesbian, gay, and bisexual adolescents: An ecological perspective. In C. J. Patterson \& A. R. D'Augelli (Eds.), Handbook of psychology and sexual orientation (pp. 87-101). New York, NY: Oxford University Press.

Rosenberg, M. (1965). Society and the adolescent self-image (Vol. 11). Princeton: Princeton University Press.

Rowley, A. A., Roesch, S. C., Jurica, B. J., \& Vaughn, A. A. (2005). Developing and validating a stress appraisal measure for minority adolescents. Journal of Adolescence, 28(4), 547-557.

Russell, S. T., \& Joyner, K. (2001). Adolescent sexual orientation and suicide risk: Evidence from a national study. American Journal of Public Health, 91(8), 1276-1281.

Ryan, C., Huebner, D., Diaz, R. M., \& Sanchez, J. (2009). Family rejection as a predictor of negative health outcomes in white and Latino lesbian, gay, and bisexual young adults. Pediatrics, 123(1), 346-352.

Safren, S. A., Hollander, G., Hart, T. A., \& Heimberg, R. G. (2001). Cognitive-behavioral therapy with lesbian, gay, and bisexual youth. Cognitive and Behavioral Practice, 8(3), 215-223. https ://doi.org/10.1016/s1077-7229(01)80056-0.

Saunders, J. B., Aasland, O. G., Babor, T. F., De la Fuente, J. R., \& Grant, M. (1993). Development of the alcohol use disorders identification test (AUDIT): WHO collaborative project on early detection of persons with harmful alcohol consumption-II. Addiction, 88(6), 791-804.

Savin-Williams, R. C. (2001). A critique of research on sexual-minority youths. Journal of Adolescence, 24(1), 5-13.

Savin-Williams, R. C., \& Diamond, L. M. (2000). Sexual identity trajectories among sexual-minority youths: Gender comparisons. Archives of Sexual Behavior, 29(6), 607-627.

Shamseer, L., Moher, D., Clarke, M., Ghersi, D., Liberati, A., Petticrew, M., \& Stewart, L. A. (2015). Preferred reporting items for systematic review and meta-analysis protocols (PRISMA-P) 2015: Elaboration and explanation. BMJ, 349, g7647.

Smith, A., Rissel, C. E., Richters, J., Grulich, A. E., \& Visser, R. O. (2003). Sex in Australia: Sexual identity, sexual attraction and sexual experience among a representative sample of adults. Australian and New Zealand Journal of Public Health, 27(2), $138-145$. 
Spataro, J., Mullen, P. E., Burgess, P. M., Wells, D. L., \& Moss, S. A. (2004). Impact of child sexual abuse on mental health. The British Journal of Psychiatry, 184(5), 416-421.

Spence, S. H. (1998). A measure of anxiety symptoms among children. Behaviour Research and Therapy, 36(5), 545-566.

Springer, K. W., Sheridan, J., Kuo, D., \& Carnes, M. (2007). Longterm physical and mental health consequences of childhood physical abuse: Results from a large population-based sample of men and women. Child Abuse \& Neglect, 31(5), 517-530.

Sterne, J. A., Hernán, M. A., Reeves, B. C., Savović, J., Berkman, N. D., Viswanathan, M., \& Boutron, I. (2016). ROBINS-I: A tool for assessing risk of bias in non-randomised studies of interventions. BMJ, 355, i4919.

Watson, D., Clark, L. A., \& Tellegen, A. (1988). Development and validation of brief measures of positive and negative affect: The PANAS scales. Journal of Personality and Social Psychology, 54(6), 1063.
Watson, R. J., Grossman, A. H., \& Russell, S. T. (2016). Sources of social support and mental health among LGB youth. Youth \& Society. https://doi.org/10.1177/0044118X16660110.

Yadegarfard, M., Meinhold-Bergmann, M. E., \& Ho, R. (2014). Family rejection, social isolation, and loneliness as predictors of negative health outcomes (depression, suicidal ideation, and sexual risk behavior) among Thai male-to-female transgender adolescents. Journal of LGBT Youth, 11(4), 347-363.

Zaki, L. F., Gross, M., \& Pachankis, J. E. (2017). Help-seeking for nonsuicidal self-injury in sexual minority adolescent and young adult females. Journal of Gay \& Lesbian Mental Health, 21(2), 171-187.

Zimet, G. D., Dahlem, N. W., Zimet, S. G., \& Farley, G. K. (1988). The multidimensional scale of perceived social support. Journal of Personality Assessment, 52(1), 30-41. 